\title{
Prolactin stimulates ubiquitination, initial internalization, and degradation of its receptor via catalytic activation of Janus kinase 2
}

\author{
Gayathri Swaminathan $^{1, *}$, Bentley Varghese ${ }^{1,2, *}$, Chellappagounder Thangavel ${ }^{1, *}$, Christopher J Carbone $^{1}$, \\ Alexander Plotnikov ${ }^{1}$, K G Suresh Kumar ${ }^{1}$, Elizabeth M Jablonski ${ }^{3}$, Charles V Clevenger ${ }^{3}$, Vincent Goffin ${ }^{4}$, \\ Luqin Deng ${ }^{\mathbf{5}}$, Stuart J Frank ${ }^{\mathbf{5}}$ and Serge Y Fuchs ${ }^{\mathbf{1}}$ \\ ${ }^{1}$ Department of Animal Biology and Mari Lowe Center for Comparative Oncology Research and ${ }^{2}$ Cell and Molecular Biology Program, Biomedical Graduate \\ School, University of Pennsylvania, 380 S University Avenue, Philadelphia, Pennsylvania 19104, USA \\ ${ }^{3}$ Department of Pathology, Northwestern University, Chicago, Illinois 60611, USA \\ ${ }^{4}$ Inserm, U845, Centre de Recherche Croissance et Signalisation, Equipe 'PRL, GH and tumours' and Université Paris Descartes, Faculté de Médecine, \\ Paris F-75015, France \\ ${ }^{5}$ Department of Cell Biology, University of Alabama at Birmingham, Birmingham, Alabama 35294, USA \\ (Correspondence should be addressed to S Y Fuchs; Email: syfuchs@vet.upenn.edu) \\ *(G Swaminathan, B Varghese, C Thangavel contributed equally to this work)
}

\begin{abstract}
Prolactin (PRL) activates its receptor to initiate signal transduction pathways (including activation of Janus kinases, Jak) but also stimulates downregulation of this receptor to limit the magnitude and duration of signaling. Degradation of the long form of PRL receptor (PRLr) depends on its phosphorylation on Ser349 that is required to facilitate PRLr ubiquitination. Signaling events that mediate PRL-induced degradation of PRLr remain to be elucidated. Here, we investigated the role of Jak2 activity in ligand-triggered increase of PRLr phosphorylation on Ser349, PRLr ubiquitination, endocytosis, and degradation. Using Jak2
\end{abstract}

reconstitution in Jak2-null cells as well as pharmacologic approaches, we found that treatment with PRL (but not with PRLr antagonist) promotes phosphorylation of PRLr on Ser349 and accelerates endocytosis of PRLr. Furthermore, PRL-stimulated PRLr phosphorylation, endocytosis, and degradation in Jak2-null cells reconstituted with wild type but not with catalytically inactive Jak2. We discuss how Jak2mediated signaling might be transduced into Ser349 phosphorylation of PRLr as well as its ubiquitination and endocytosis.

Journal of Endocrinology (2008) 196, R1-R7

\section{Introduction}

The prolactin receptor (PRLr) is a member of the cytokine receptor superfamily that transduces the signals of the pituitary hormone PRL, which is implicated in numerous biological functions (including mammary gland development and lactation) and plays an important role in mammary tumorigenesis (Bole-Feysot et al. 1998, Clevenger et al. 1998, 2003, Goffin et al. 2002, Vera-Lastra et al. 2002). The fine-tuning of PRL signaling is achieved by balancing/counter-balancing PRL-generated signals with concomitant down-modulation of PRLr, which limits availability of the receptor on the surface to bind PRL (Djiane et al. 1979, 1981). This mechanism plays a pivotal role in ligand-specific negative control or PRL signaling (Clevenger et al. 2003).
An existing paradigm for mechanisms that govern downregulation of signaling receptors suggests that activated signaling leads to receptor ubiquitination that mediates efficient endocytosis and lysosomal degradation of the receptors (reviewed in Hicke (2001). Negative regulation of PRL signaling indeed involves phosphorylation of PRLr on Ser349 and recruitment of $\beta$-transducin repeats-containing protein $(\beta \operatorname{Trcp})$-containing E3 ubiquitin ligase that facilitates ubiquitination and subsequent degradation of PRLr (Li et al. 2004). This mode of negative regulation has also been observed for other cytokine receptors including erythropoietin receptor (EpoR; Meyer et al. 2007) and Type I interferon receptor subunit (IFNAR1; Kumar et al. 2003, 2004). Activation of Janus kinase 2 (Jak2) is a proximal event, which occurs following PRL stimulation and plays a vital role 
in PRL-induced signaling (reviewed in (Clevenger \& Kline 2001)). Besides activating canonical Jak-Stat pathway, PRL also activates other signaling kinases such as mitogen-activated protein kinase, Src, and phosphoinositol 3-kinase. However, role of these pathways in PRLr ubiquitination, endocytosis, and degradation is yet to be characterized.

In this study, we report that Jak2 catalytic activation is required for PRL-induced increase in PRLr phosphorylation on Ser349 and ensuing PRLr ubiquitination. We also found that kinase activity of Jak2 contributes to the regulation of PRLr endocytosis and degradation. Furthermore, data obtained using a PRLr that lacks intracellular tyrosine residues indicate that phosphorylation of these residues might play a role in transducing the signal from the ligand to PRLr phosphorylation on Ser349 and PRLr proteolysis.

\section{Materials and Methods}

\section{Cell culture and plasmids}

Human embryo kidney 293T cells, Jak2-null $\gamma 2 \mathrm{~A}$ cells (Kohlhuber et al. 1997), and their derivatives were maintained and transfected as described elsewhere (Li et al. 2004, Deng et al. 2007). Plasmids for expression of flag-tagged (Li et al. 2004) or V5-tagged (Miller et al. 2005) PRLr, as well as JAK2 ${ }^{\mathrm{WT}}$ or JAK2 ${ }^{\mathrm{K} 882 \mathrm{D}}$ (Huang et al. 2001) were previously described. Human PRLr with a hemaglutinin (HA)-tag inserted after the signal sequence at the $\mathrm{N}$-terminus between amino acids Q25 and L26 was constructed by the overlap PCR method using the following primers: $5^{\prime}$-GGCAGTACATCAATGGGCGTGG-3', $5^{\prime}$-ACTCACGGGGATTTCCAAGTCTCCACCC-3' ${ }^{\prime}, 5^{\prime}$-ATAGTCAGGTACATCGTATGGGTACTGT CCATTCAGAAGGCAGG-3', 5'-CCATACGATGTACCTGACTATGCATTACCTCCTGGAAAACCTGAG-3', 5'-GATGCATGCTCGAGCGTGAAAGGAGTGTGTAAAACATGCG-3', and 5'-CTGAGAATCTTAAACTCTGTTTGCTGCC-3'. The overlap PCR products were subjected to restriction enzyme digestion with $\mathrm{KpnI}$ and AgeI followed by sub-cloning into similarly digested pCDNA3PRLr ${ }^{\mathrm{wt}}$. All the plasmid constructs were verified by sequencing.

\section{Reagents, antibodies, and immunotechniques}

Antibodies against FLAG tag (M2, Sigma), V5 tag (Invitrogen), $\beta$-actin (Sigma), ubiquitin (FK2, Biomol, Plymouth Meeting, PA, USA), pSTAT5, STAT5 (Cell Signaling, Danvero, CA, USA), Jak2, anti-phospho-tyrosine (Upstate Biotech, Lake Placid, NY, USA), and PRLr (Zymed, San Francisco, CA, USA and Santa Cruz, Santa Cruz, CA, USA) were purchased. PhophoSer349 PRLr antibody has been described previously (Li et al. 2006). Human PRL was purchased from the National Hormone and Peptide program (A F Parlow). PRLr antagonist $P R L^{\Delta 1-9-G 129 R}$ was produced and purified as previously described (Bernichtein et al. 2003). AG490 and PP1 (Calbiochem, San Diego, CA, USA) were purchased. In vivo ubiquitination analysis, immunoprecipitation, and immunoblotting were performed as described previously (Li et al. 2004). For PRLr degradation assay, $\gamma 2 \mathrm{~A}$ cells were serum starved overnight followed by stimulation with $200 \mathrm{ng} / \mathrm{ml} \mathrm{PRL}$ in the presence of $50 \mu \mathrm{g} / \mathrm{ml}$ cycloheximide (CHX chase).

\section{Fluorescence-based internalization assay}

This assay measures the loss of cell-surface immunoreactivity of epitope tagged or endogenous receptors using an ELISA assay as described previously (Barriere et al. 2006) with the following modifications. Briefly, 293T or $\gamma 2 \mathrm{~A}$ cells transfected with HA-PRLr and other constructs as indicated were serum starved and chilled on ice. Internalization was initiated by incubation of cells with serum-free DMEM for indicated time periods at $37^{\circ} \mathrm{C}$ and terminated by placing the plate on ice. Levels of cellsurface HA-PRLr were analyzed by ELISA using anti-HA primary antibody and horseradish peroxidase-conjugated goat anti-mouse secondary antibody (Molecular Probes, Eugene, OR, USA) followed by incubation with AmplexRed Ultra Reagent (Molecular Probes). Resulting fluorescence was measured (530 nm for excitation and $590 \mathrm{~nm}$ for emission) and expressed after subtracting the value obtained with mocktransfected cellsas percentage of fluorescence registered prior to internalization. Average results of three independent experiments (each in quadruplicate \pm s.E.M.) are depicted.

\section{Surface biotinylation-based internalization assay}

Cell-surface biotinylation that uses immunoblotting analysis to detect biotinylated proteins that were protected from de-biotinylation due to their internalization was carried out as described elsewhere (Hammond et al. 2003). Briefly, surface of cells that stably express PRLr-Flag and either wildtype or kinase-deficient Jak2 was biotinylated on ice. After that, cells were either kept on ice (time point ' 0 ') or incubated at $37^{\circ} \mathrm{C}$ with PRL for $7 \cdot 5 \mathrm{~min}$. Then, cells were returned to ice and either left untreated (point ' $0{ }^{\star}$ ', $100 \%$ of biotinilyation) or subjected to selective removal of cell-surface biotin. After numerous washes, cells were lysed and biotinylated proteins were recovered by incubating with immobilized NeutrAvidin (Pierce, Rockford, IL, USA) overnight, washed, and analyzed by immunoblotting with anti-Flag M2 antibody.

\section{Results and discussion}

Phosphorylation of PRLr on Ser349 is a key regulator of its ability to recruit the $\beta \operatorname{Trcp}$ E3 ubiquitin ligase and to undergo ubiquitination-mediated degradation (Li et al. 2004). In human embryo kidney $293 \mathrm{~T}$ cells, which respond to PRL while displaying relatively low basal levels of PRLr phosphorylation on Ser349 as well as PRLr levels ( $\mathrm{Li}$ et al. 2004), we observed that treatment of these cells with PRL (but not with signaling-deficient $\mathrm{PRL}^{\Delta 1-9-\mathrm{G} 129 \mathrm{R}}$ mutant (Goffin et al. 2005)) increased the extent of phosphorylation of PRLr on Ser349 (Fig. 1A). The extent of this 

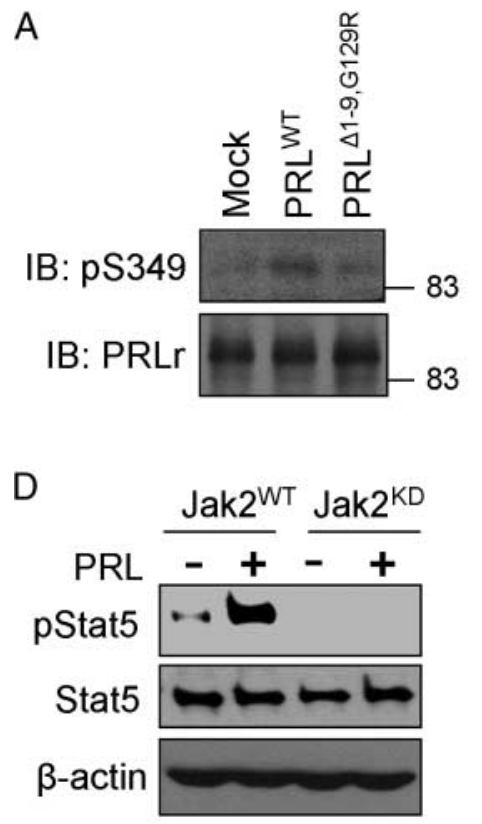

B

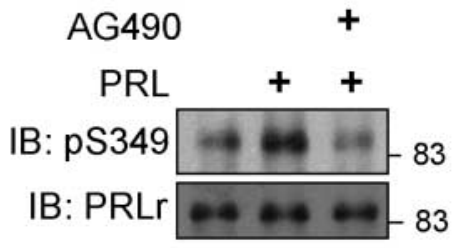

$\mathrm{E}$

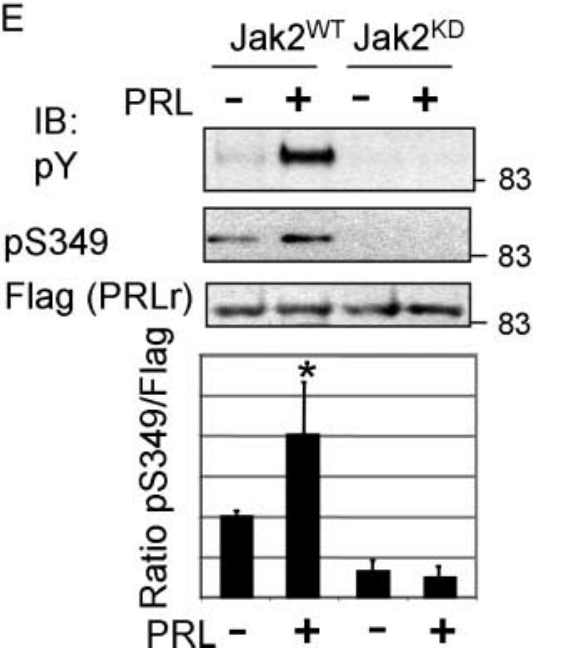

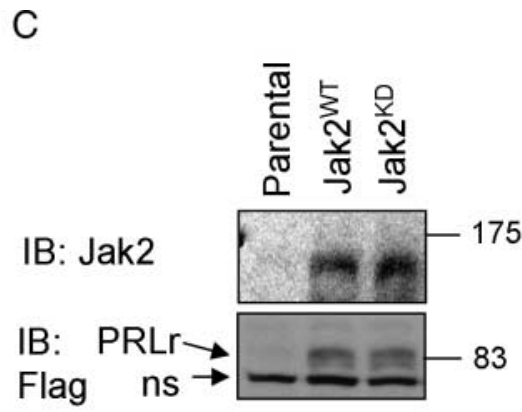

$\mathrm{F}$

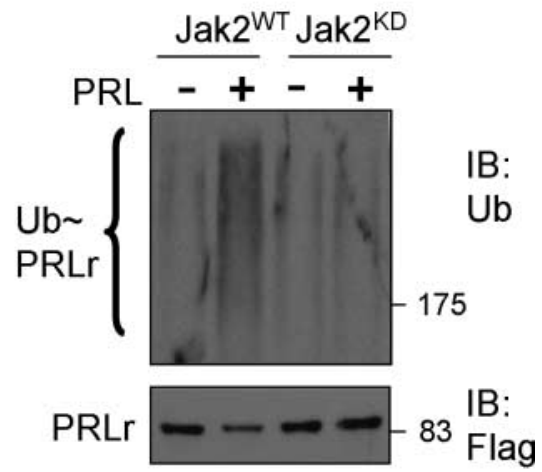

Figure 1 Catalytic activity of Jak2 regulates PRL-induced phosphorylation of PRLr on Ser349 and PRLr ubiquitination. (A) Phosphorylation of endogenous PRLr from 293T cells treated with $100 \mathrm{ng} / \mathrm{ml}$ of either PRL or PRLr antagonist (PRL ${ }^{\Delta 1-9, G 129 R}$ ) for 5 min was analyzed by immunoprecipitation of PRLr followed by immunoblotting with indicated antibodies. (B) Phosphorylation of endogenous PRLr from 293T cells pretreated with either Jak inhibitor (AG490, $50 \mu \mathrm{M}$ ) or vehicle (DMSO) for $2 \mathrm{~h}$ before adding PRL (100 $\mathrm{ng} / \mathrm{ml}$ ) for $5 \mathrm{~min}$. Loading of samples was normalized to obtain comparable levels of total PRLr in all lanes. Analysis was carried out as described in panel A. (C) Levels of Flag-PRLr and Jak2 (wild-type, WT, or kinase-deficient, KD) re-expressed in $\gamma 2 \mathrm{~A}$ cells were analyzed by immunoblotting using the indicated antibodies. NS, nonspecific band. (D) Activation of Stat 5 and Erk in $\gamma 2 \mathrm{~A}$ cells reconstituted either with wild-type or kinase-deficient Jak2 was analyzed by immunoblotting using indicated antibodies that recognize phosphorylated or total proteins. Immunoblotting using anti- $\beta$-actin antibody represents a loading control. (E) Phosphorylation of PRLr on Tyr residues (pY, upper panel) or on Ser349 (pS349, middle panel) in $\gamma 2 \mathrm{~A}$ cells expressing indicated Jak2 and treated as indicated with PRL (200 ng/ml for $30 \mathrm{~min}$ ) was analyzed by immunoprecipitation of FlagPRLr using anti-Flag antibody followed by immunoblotting using indicated phospho-specific antibodies. Ratios between pS349 and Flag signals corresponding to cell types and treatments are calculated as an average from four independent experiments $( \pm$ s.E.M.) and depicted in the graph below. Asterisk denotes $P<0 \cdot 05$ in the $t$-test relative to untreated Jak2 ${ }^{\mathrm{WT}}$ cells. (F) Flag-PRLr stringently immunopurified from denatured lysates of $\gamma 2 \mathrm{~A}$ cells expressing the indicated Jak2 and treated where indicated with PRL (200 ng/ml for $30 \mathrm{~min})$ was analyzed by immunoblotting using either anti-ubiquitin (upper panel) or anti-Flag (lower panel) antibodies.

phosphorylation was reduced by pretreatment of cells with Jak inhibitor (AG490, Fig. 1B) indicating that activity of Jak plays an important role in this pathway.

Although PRL is capable of activating other Jak including Jak1 (Neilson et al. 2007), Jak2 is the major Jak associated with PRLr (Rui et al. 1994). To delineate the role of Jak2 in PRLr serine phosphorylation, we employed a reconstitution system by stably expressing FLAG-tagged PRLr and either wild-type Jak2 (Jak2 $\left.{ }^{\mathrm{WT}}\right)$ or kinase-deficient Jak2 mutant $\mathrm{Jak} 2^{\mathrm{K} 882 \mathrm{D}}\left(\mathrm{Jak} 2^{\mathrm{KD}}\right)$ in Jak2-null $\gamma 2 \mathrm{~A}$ fibrosarcoma cells (Kohlhuber et al. 1997). Clones with comparable expression of transfected proteins (Fig. 1C) were chosen for analysis. As expected, cells expressing Jak2 ${ }^{\mathrm{WT}}$ (but not $\mathrm{Jak} 2^{\mathrm{KD}}$ ) responded to PRL treatment with a robust increase in tyrosine phosphorylation of Stat5 (Fig. 1D) and PRLr (Fig. 1E). A modest but consistent induction of Ser349 phosphorylation (Fig. 1E) and PRLr ubiquitination (Fig. 1F) was observed only in the cells that expressed catalytically active Jak2. These data provide genetic evidence in support of a role for Jak2 kinase activity in PRLr Ser349 phosphorylation and PRLr ubiquitination.

Ubiquitination of cell-surface proteins can serve as an efficient endocytosis signal (Hicke 2001). We next analyzed the rate of PRLr endocytosis using a highly sensitive 
fluorescence-based endocytosis assay that allows for the analysis of internalization of receptor itself (see Materials and Methods). PRL significantly increased the initial internalization rate of its receptor in $293 \mathrm{~T}$ cells. PRLr antagonist PRL ${ }^{\Delta 1-9, G 129 R}$ had no effect alone but reversed the stimulation of PRLr internalization by wild-type PRL (Fig. 2A). These results indicate that PRL-induced signaling is likely to promote receptor internalization.

To determine the role of Jak2 kinase activity on PRLr endocytosis, we have pretreated $293 \mathrm{~T}$ cells with either Jak
A

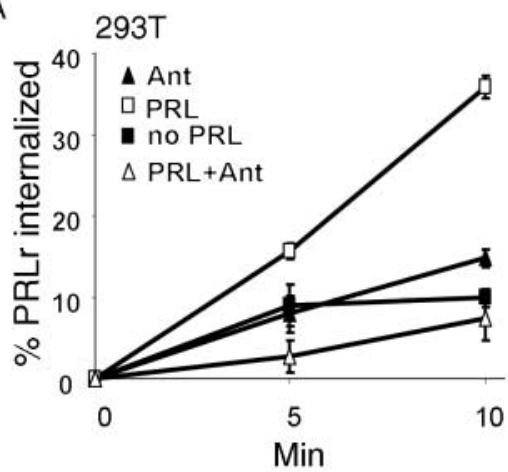

C

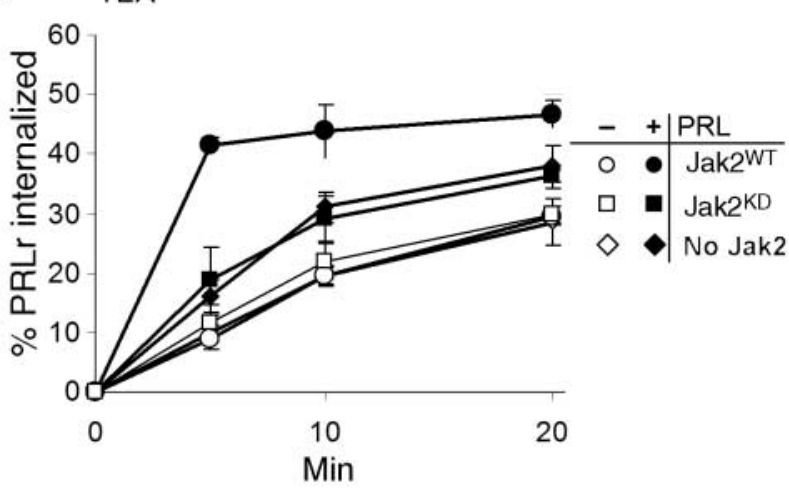

B

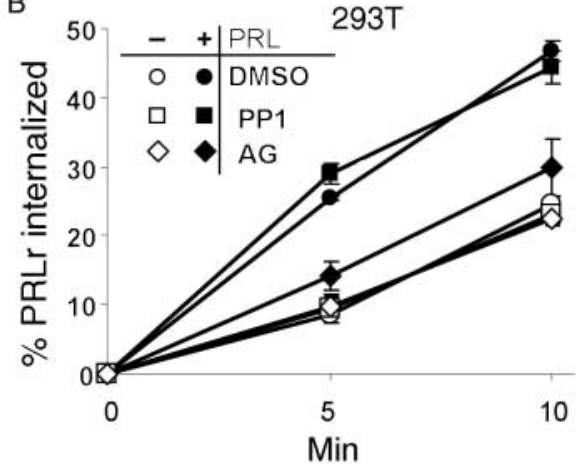

D

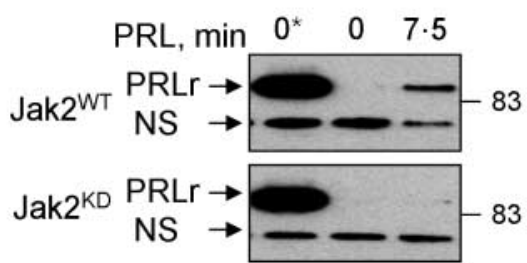

Figure 2 PRL signaling via Jak2 regulates initial internalization of PRLr. (A) Effect of PRL (open squares and open triangles) or PRLr antagonist ( $\mathrm{PRL}^{\Delta 1-9, \mathrm{G} 129 \mathrm{R}}$, closed and open triangles) on the initial rate of internalization of amino-terminally HA-tagged PRLr expressed in 293T cells measured by a fluorescent assay as described in Materials and Methods. (B) Effect of Jak inhibitor AG490 (50 $\mu$ M, diamonds) or Src inhibitor PP1 $(10 \mu \mathrm{M}$, squares) on the initial rate of internalization of PRLr in 293T cells in the presence (closed symbols) or absence (open symbols) of PRL $(50 \mathrm{ng} / \mathrm{ml})$ measured by a fluorescent assay. Inhibitors were added to cells $40 \mathrm{~min}$ before the internalization start. Controls are represented by treatment of cells with vehicle (DMSO, closed or open circles). (C) Effect of transient expression of Jak2 ${ }^{\mathrm{WT}}$ (circles) or Jak2 ${ }^{\mathrm{KD}}$ (squares) on the initial rate of internalization of PRLr in $\gamma 2 \mathrm{~A}$ cells in the presence (closed symbols) or absence (open symbols) of PRL $(50 \mathrm{ng} / \mathrm{ml}$ ) measured by a fluorescent assay. Controls are represented by internalization of PRLr in cells that did not receive any Jak2 (closed or open diamonds circles). Right panel depicts immunoblotting analysis of Jak2 expression in these cells. (D) Internalization of Flag-tagged PRLr expressed in $\gamma 2 \mathrm{~A}$ that harbor indicated Jak2 species was measured by reversible surface biotinylation assay. Neutravidin beads pull downs were analyzed by immunoblotting using anti-Flag antibody. Appearance of Flag-tagged PRLr at time points after zero indicates the levels of internalized PRLr species that were protected from removal of biotin label from cell surface. ' 0 *' denotes samples that did not undergo biotin removal ('100\% biotinylation'). 'NS', nonspecific band. 
inhibitor AG490 or potent Src inhibitor PP1 and then measured PRLr internalization in the presence or absence of the ligand. While neither of inhibitors affected basal PRLr internalization, the ligand-stimulated endocytosis of PRLr was impaired in cells treated with AG490 but not with Src inhibitor (Fig. 2B). Furthermore, analysis of PRLr internalization in $\gamma 2 \mathrm{~A}$-derived cells revealed that, while re-expression of wild-type kinase significantly increased PRLr internalization, this effect was not observed in cells expressing inactive Jak2 (Fig. 2C). Given that inactive Jak2 is yet implicated in maturation and cell-surface delivery or PRLr and EpoR (Huang et al. 2001), these data also suggest that, unlike for receptor maturation, Jak2 role in internalization does require its protein kinase activity. Similar results were seen in stable clones using reversible surface biotinylation assay (Fig. 2D). Together, these data suggest that catalytic activity of Jak2 is required for ligand-facilitated acceleration of initial rate of PRLr internalization.
Given that endocytosis of PRLr might ultimately lead to its degradation, we assessed the rate of PRLr proteolysis using a CHX chase assay in the presence of PRL. This assay was validated by comparing the rates of degradation between wild-type PRLr and its stabilized mutant that lacks Ser349 and thus is unable to recruit $\beta \operatorname{Trcp}$ and to undergo efficient ubiquitination (Li et al. 2004). As seen in Fig. 3A, PRLr ${ }^{\text {S349A }}$ mutant exhibited much greater stability than PRLr ${ }^{\mathrm{WT}}$ in $\gamma 2 \mathrm{~A}$ cells that express catalytically active Jak2. Remarkably, degradation of PRLr ${ }^{\mathrm{WT}}$ was noticeably delayed in $\mathrm{Jak}^{\mathrm{KD}}$ cells. Together, these data suggest that Jak2 catalytic activity is required for efficient ubiquitination, internalization, and degradation of PRLr.

Jak2 activation in response to PRL results in tyrosine phosphorylation of PRLr. To investigate whether tyrosine phosphorylation of PRLr by Jak2 affects Ser349 phosphorylation of PRLr and its degradation we established $\gamma 2 \mathrm{~A}$ cell lines stably expressing Jak2 ${ }^{\mathrm{WT}}$ and either wild-type PRLr
A

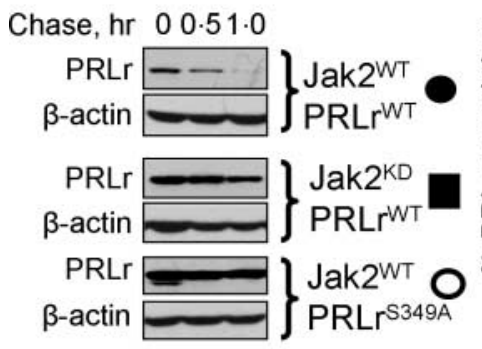

C

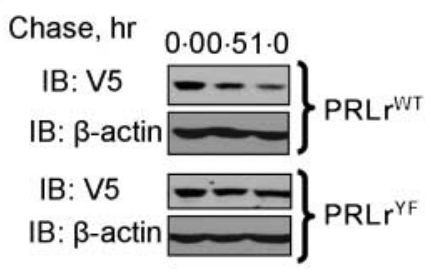

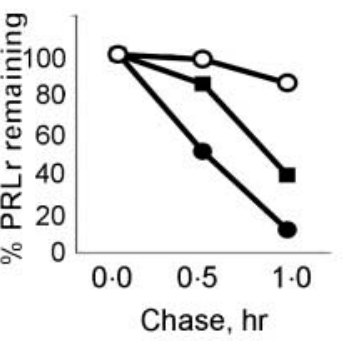

Chase, hr

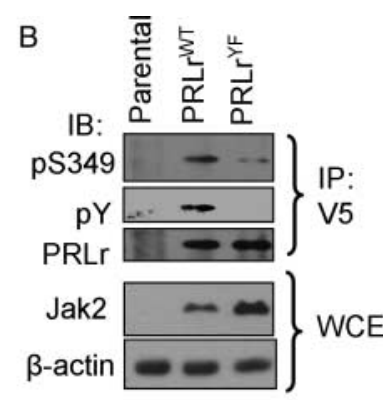

Figure 3 Rapid degradation of PRLr in response to PRL requires Jak2 catalytic activity and PRLr tyrosine residues. (A) Degradation of Flag-PRLr (wild type, closed symbols, or S349A mutant, open circle) in $\gamma 2 \mathrm{~A}$ cells expressing either wild type (circles) or catalytically inactive (squares) Jak2 species in the presence of PRL $(200 \mathrm{ng} / \mathrm{ml})$ was analyzed by cycloheximide chase followed by immunoblotting analysis using antiFlag (upper panels) antibody to detect exogenous PRLr or using anti- $\beta$-actin antibody (lower panels) as a loading control. Symbols correspond to graphic depiction of the results (shown in the right panel) that reflects the quantified PRLr levels calculated as a \% of receptor remaining compared with time point ' 0 ' $(100 \%)$. A representative of three independent experiments is shown. (B) Phosphorylation of PRLr on Ser349 (upper panel) or on Tyr residues (middle panel) in $\gamma 2 \mathrm{~A}$ cells expressing Jak2 ${ }^{\mathrm{WT}}$ and PRLr as indicated. Cells were treated with PRL ( $200 \mathrm{ng} / \mathrm{ml}$ for $25 \mathrm{~min}$ ) before harvesting. Lysates were analyzed by immunoprecipitation of V5-tagged PRLr using anti-V5 antibody followed by immunoblotting using indicated phospho-specific antibodies. Levels of Jak2 in whole cell extracts ('WCE') were also analyzed by immunoblotting (lower panel). (C) Degradation of PRLr and its mutants was assessed by cycloheximide chase (as in panel A) followed by immunoblotting analyses of PRLr using anti-V5 antibody (upper panels) and of actin (as a loading control, lower panels) as indicated. Symbols correspond to the graphical depiction of the results shown in the right panel (calculated as in panel A). A representative of three independent experiments is shown. 
(PRLr ${ }^{\mathrm{WT}}$ ) or PRLr mutants that harbor Tyr to Phe substitutions at all intracellular tyrosine positions $\left(\mathrm{PRLr}{ }^{\mathrm{YF}}\right)$. These proteins were immunopurified from PRL-treated cells and analyzed by anti-phosphotyrosine and anti-Ser349 antibodies. Remarkably, not only Tyr phosphorylation but also Ser349 phosphorylation was nearly abolished in PRLr ${ }^{\mathrm{YF}}$ (Fig. 3B). Furthermore, this mutant exhibited a longer half life in CHX chase assay (Fig. 3C). These results suggest that tyrosine phosphorylation of intracellular domain of PRLr plays an important role in controlling the rate of its Ser349 phosphorylation and degradation.

The current study is the first to identify Jak2 tyrosine kinase as an important modulator of PRLr stability. The pharmacologic and genetic evidence suggests that PRL-induced activation of Jak2 promotes phosphorylation of Ser349 within the phosphodegron of PRLr as well as PRLr ubiquitination, endocytosis, and degradation. These data are in line with a model for putative mechanisms by which PRL stimulates downregulation of its receptor. This model suggests that ligand-induced activation of Jak2 (and, perhaps, ensuing tyrosine phosphorylation of the intracellular tail of PRLr) facilitate the recruitment and/or activation of factors contributing to Ser349 phosphorylation such as a yet to be identified serine kinase (although Tyr-independent mechanisms of such kinase activation cannot be ruled out). A hypothetical serine kinase that is capable of phosphorylating PRLr on Ser349 should conceptually be characterized by its ability to be activated/recruited to PRLr in a Jak2-dependent manner. An expected outcome of such event would be an increase in PRLr Ser349 phosphorylation, which enables PRLr ubiquitination followed by acceleration of endocytosis and degradation of PRLr.

Our hypothesis is consistent with activation of Jak2 being perhaps the most immediate segment of PRLr signaling that is important for both mediating downstream signaling effects (including an activation of Stat proteins) and in restricting the magnitude and duration of this downstream signaling via accelerating the degradation of the receptor. It is plausible that such a mechanism is common for a number of cytokine and protein hormone receptors. Indeed, recent studies suggest that, in its requirement for Jak activation, PRLr is similar to several other receptors, whose signaling promotes their own degradation through associated Jak. In addition to Jak2 being a key player in the degradation of EpoR (Walrafen et al. 2005) and growth hormone receptor (Deng et al. 2007), activation of other associated Jak was shown to regulate ubiquitination and turnover of IFNAR1 and IL-5R (Marijanovic et al. 2006, Martinez-Moczygemba et al. 2007).

Given that Jak2 activity is required for maximal efficiency of both ubiquitination and endocytosis of PRLr, a detailed investigation of the role of PRLr ubiquitination in internalization and post-internalization sorting is warranted. However, considering a well-established role of SOCS proteins in ubiquitination and degradation of Jak (including Jak2 (Ali et al. 2003)), it might be also important to determine whether ubiquitination- or proteasome-dependent degradation of Jak2 might indirectly affect internalization (and, thus, lysosomal degradation) of PRLr. Indeed, recently the role of SOCS3 in lysosomal turnover of the G-CSF receptor has been demonstrated (Irandoust et al. 2007). Furthermore, an additional role of other PRL-induced pathways in PRLr endocytosis cannot be ruled out given that Src inhibitor impeded endocytosis of radiolabeled PRL in COS cells overexpressing bovine PRLr (Lu et al. 2002). It is plausible that a second, Src-dependent pathway might be responsible for downregulation of PRLr in Ser349 phosphorylation- and ubiquitination-independent manner. In this regard, it is worth noting that c-Src can be activated by PRL independent of Jak2 in chicken embryo fibroblasts (Fresno Vara et al. 2000). These pathways might either synergize to facilitate optimal/efficient PRLr downregulation or might differentially contribute to PRLr endocytosis and degradation in a cell-type-specific manner. Future studies are underway to characterize both pathways and determination of the role of PRLr ubiquitination in these mechanisms.

\section{Acknowledgements}

We thank Drs A F Parlow, Z Ronai, G Stark, and H Lodish for the gifts of reagents and to Jamie DeMaria for technical assistance. We are indebted to Linda Schuler for critical evaluation of this manuscript. This work is supported by NIH grants CA115281 (to S Y F), DK058259 (to S J F), CA069294 and CA092265 (to C V C), and by funding from Inserm (Institut National de la Santé et de la Recherche Médicale - to V G). The authors declare that there is no conflict of interest that would prejudice the impartiality of this scientific work.

\section{References}

Ali S, Nouhi Z \& Chughtai N 2003 SHP-2 regulates SOCS-1 mediates Janus Kinase-2 ubiquitination/degradation downstream of the prolactin receptor. Journal of Biological Chemistry 278 52021-52031.

Barriere H, Nemes C, Lechardeur D, Khan-Mohammad M, Fruh K \& Lukacs GL 2006 Molecular basis of oligoubiquitin-dependent internalization of membrane proteins in Mammalian cells. Traffic 7 282-297.

Bernichtein S, Kayser C, Dillner K, Moulin S, Kopchick JJ, Martial JA, Norstedt G, Isaksson O, Kelly PA \& Goffin V 2003 Development of pure prolactin receptor antagonists. Journal of Biological Chemistry 278 35988-35999.

Bole-Feysot C, Goffin V, Edery M, Binart N \& Kelly PA 1998 Prolactin (PRL), and its receptor: actions, signal transduction pathways and phenotypes observed in PRL receptor knockout mice. Endocrine Reviews 19 225-268.

Clevenger CV \& Kline JB 2001 Prolactin receptor signal transduction. Lupus $10706-718$

Clevenger CV, Freier DO \& Kline JB 1998 Prolactin receptor signal transduction in cells of the immune system. Journal of Endocrinology 157 187-197.

Clevenger CV, Furth PA, Hankinson SE \& Schuler LA 2003 The role of prolactin in mammary carcinoma. Endocrine Reviews 24 1-27.

Deng L, He K, Wang X, Yang N, Thangavel C, Jiang J, Fuchs SY \& Frank SJ 2007 Determinants of growth hormone receptor downregulation. Molecular Endocinology 21 1537-1551. 
Djiane J, Clauser H \& Kelly PA 1979 Rapid down-regulation of prolactin receptors in mammary gland and liver. Biochemical and Biophysical Research Communications 90 1371-1378.

Djiane J, Houdebine LM \& Kelly PA 1981 Down-regulation of prolactin receptors in rabbit mammary gland: differential subcellular localization. Proceedings of Society Experimental Biology and Medicine 168 378-381.

Fresno Vara JA, Carretero MV, Geronimo H, Ballmer-Hofer K \& MartinPerez J 2000 Stimulation of c-Src by prolactin is independent of Jak2. Biochemical Journal 345 17-24.

Goffin V, Binart N, Touraine P \& Kelly PA 2002 Prolactin: the new biology of an old hormone. Annual Review of Physiology 64 47-67.

Goffin V, Bernichtein S, Touraine P \& Kelly PA 2005 Development and potential clinical uses of human prolactin receptor antagonists. Endocrine Reviews 26 400-422.

Hammond DE, Carter S, McCullough J, Urbe S, Vande Woude G \& Clague MJ 2003 Endosomal dynamics of Met determine signaling output. Molecular Biology of the Cell 14 1346-1354.

Hicke L 2001 Protein regulation by monoubiquitin. Nature Review. Molecular and Cellular Biology 2 195-201.

Huang LJ, Constantinescu SN \& Lodish HF 2001 The N-terminal domain of Janus kinase 2 is required for Golgi processing and cell surface expression of erythropoietin receptor. Molecular Cell 8 1327-1338.

Irandoust MI, Aarts LH, Roovers O, Gits J, Erkeland SJ \& Touw IP 2007 Suppressor of cytokine signaling 3 controls lysosomal routing of G-CSF receptor. EMBO Journal 26 1782-1793.

Kohlhuber F, Rogers NC, Watling D, Feng J, Guschin D, Briscoe J, Witthuhn BA, Kotenko SV, Pestka S, Stark GR et al. 1997 A JAK1/JAK2 chimera can sustain alpha and gamma interferon responses. Molecular Cell Biology 17 695-706.

Kumar KG, Tang W, Ravindranath AK, Clark WA, Croze E \& Fuchs SY 2003 $\mathrm{SCF}(\mathrm{HOS})$, ubiquitin ligase mediates the ligand-induced down-regulation of the interferon-alpha receptor. EMBOJ 22 5480-5490.

Kumar KG, Krolewski JJ \& Fuchs SY 2004 Phosphorylation and specific ubiquitin acceptor sites are required for ubiquitination and degradation of the IFNAR1 subunit of type I interferon receptor. Journal of Biological Chemistry 279 46614-46620.

Li Y, Kumar KG, Tang W, Spiegelman VS \& Fuchs SY 2004 Negative regulation of prolactin receptor stability and signaling mediated by SCF(beta-TrCP) E3 ubiquitin ligase. Molecular Cell Biology 24 4038-4048.
Li Y, Clevenger CV, Minkovsky N, Kumar KG, Raghunath PN, Tomaszewski JE, Spiegelman VS \& Fuchs SY 2006 Stabilization of prolactin receptor in breast cancer cells. Oncogene 25 1896-1902.

Lu JC, Scott P, Strous GJ \& Schuler LA 2002 Multiple internalization motifs differentially used by prolactin receptor isoforms mediate similar endocytic pathways. Molecular Endocinology 16 2515-2527.

Marijanovic Z, Ragimbeau J, Kumar KG, Fuchs SY \& Pellegrini S 2006 TYK2 activity promotes ligand-induced IFNAR1 proteolysis. Biochemical Journal 397 31-38.

Martinez-Moczygemba M, Huston DP \& Lei JT 2007 JAK kinases control IL-5 receptor ubiquitination, degradation, and internalization. Journal of Leukocyte Biology 81 1137-1148.

Meyer L, Deau B, Forejtnikova H, Dumenil D, Margottin-Goguet F, Lacombe C, Mayeux P \& Verdier F 2007 beta-Trcp mediates ubiquitination and degradation of the erythropoietin receptor and controls cell proliferation. Blood 109 5215-5222.

Miller SL, DeMaria JE, Freier DO, Riegel AM \& Clevenger CV 2005 Novel association of Vav2 and Nek3 modulates signaling through the human prolactin receptor. Molecular Endocinology 19 939-949.

Neilson LM, Zhu J, Xie J, Malabarba MG, Sakamoto K, Wagner KU, Kirken RA \& Rui H 2007 Coactivation of Jak1 positively modulates prolactin-Jak2 signaling in breast cancer: recruitment of ERK and Stat 3 and enhancement of Akt and Stat5a/b pathways. Molecular Endocinology 21 2218-2232.

Rui H, Kirken RA \& Farrar WL 1994 Activation of receptor-associated tyrosine kinase JAK2 by prolactin. Journal of Biological Chemistry $\mathbf{2 6 9}$ $5364-5368$.

Vera-Lastra O, Jara LJ \& Espinoza LR 2002 Prolactin and autoimmunity. Autoimmunity Reviews 1 360-364.

Walrafen P, Verdier F, Kadri Z, Chretien S, Lacombe C \& Mayeux P 2005 Both proteasomes and lysosomes degrade the activated erythropoietin receptor. Blood 105 600-608.

Received in final form 20 November 2007

Accepted 22 November 2007

Made available online as an Accepted Preprint 22 November 2007 